Check for updates

Cite this: RSC Adv., 2018, 8, 28891

Received 21st June 2018

Accepted 7th August 2018

DOI: $10.1039 / \mathrm{c} 8 \mathrm{ra0} 05306 \mathrm{e}$

rsc.li/rsc-advances

\section{Controlled organocatalyzed D,L-lactide ring- opening polymerizations: synthesis of low molecular weight oligomers $\dagger$}

\author{
M. R. Newman, (D) ab S. G. Russell ${ }^{\text {c }}$ and D. S. W. Benoit (iD *abc \\ A systematic approach to the synthesis of organocatalyzed oligo(D,L-lactide) demonstrates that choice of \\ initiator, catalytic ratio, and reaction time yields well-controlled oligomers. Ring-opening polymerization \\ of $D, L$-lactide with the initiator $\alpha$-methyl propargyl alcohol, a secondary alcohol, used in excess of 4- \\ dimethylaminopyridine catalyst mitigates cyclicization, transesterification, and catalyst-initiated side \\ reactions. This approach enables the design of uniform lactide oligomers for controlled release \\ applications, such as delivery systems for drugs, prodrugs, and molecular sensors.
}

Poly(lactide) (PLA) is a versatile polymer with properties suitable for a range of controlled release applications. Molecular weight and copolymer composition control degradation and drug release, with degradation yielding biocompatible lactic acid products. PLA and copolymers of lactide and glycolide (PLGA) have been used pre-clinically and clinically for release of drugs, ${ }^{1-3}$ prodrugs ${ }^{4-6}$ and molecular sensors. ${ }^{7-9}$ Highly reproducible PLA chemistries are particularly important to ensure control over the release of drugs with narrow therapeutic windows and to enhance efficacy by reducing dependence on patient compliance. ${ }^{10-13}$ Stannous octoate is commonly employed as an organometallic catalyst of lactide ring-opening polymerization (ROP). ${ }^{14,15}$ However, tin catalysts, which are challenging to fully remove during purification, can result in toxicity. ${ }^{16}$ Alternatives such as strongly basic amine organocatalysts are favored, particularly 4-dimethylaminopyridine (DMAP), which was pioneered by Nederberg et al. ${ }^{17}$ DMAPmediated ROP is used for one-pot PLA polymerizations and conjugations, ${ }^{18}$ diblock or triblock copolymerizations with lactide as a first or second block, ${ }^{19-21}$ grafting lactide to cellulose polymer fibers, ${ }^{22}$ and synthesizing star-shaped/cross-linked PLA networks. ${ }^{23}$ PLA has also been exploited to tether and release drugs from linear polymers and hydrogel depots. ${ }^{24}$ Drug tethers are typically low molecular weight oligo(lactide) composed of fewer than seven lactide repeat units to avoid crystallinity and associated challenges with solubility and control over

\footnotetext{
${ }^{a}$ Department of Biomedical Engineering, University of Rochester, Rochester, NY 14627, USA.E-mail: benoit@bme.rochester.edu

${ }^{b}$ Center for Musculoskeletal Research, University of Rochester Medical Center, Rochester, NY 14642, USA

'Department of Chemical Engineering, University of Rochester, Rochester, NY 14627, USA

$\dagger$ Electronic supplementary information (ESI) available. See DOI: 10.1039/c8ra05306e
}

degradation rates..$^{25}$ Self-catalysis, or direct polycondensation, of lactic acid at increased temperature and reduced pressure for an extended time yields low-molecular weight (800-3200 Da) oligo(lactide), in contrast to organocatalysts that are commonly employed for high molecular weight PLA synthesis. However, extensive setup and environmental control decrease the accessibility of these reactions. ${ }^{26,27}$ Furthermore, with neither an initiator nor a catalyst used in polycondensation, mixtures of $\alpha$ hydroxy and $\omega$-carboxy PLA are formed, limiting the versatility of post-polymerization drug functionalization. ${ }^{28}$ Alternatively, click chemistry ${ }^{29}$ may be exploited to control subsequent modification of oligo(lactide) by employing a 'clickable' alcohol to initiate oligo(lactide) synthesis. ${ }^{30}$

Here, we explored bulk ROP of D,L-lactide by propargyl alcohol initiator and DMAP catalyst to synthesize low molecular weight oligo(lactide) linkers. To enable subsequent click reactions and to mitigate crystallinity, propargyl alcohol (PA) and D,L-lactide (L) were used. ${ }^{27}$ Although not studied here, similar approaches have shown products do not epimerize, and we expect oligomers to be atactic and amorphous. ${ }^{17}$ To investigate the molecular weight and polydispersity of oligo(lactide), an initial polymerization was designed similar to that of Nederberg et al. ${ }^{17}$ and Coulembier and Dubois ${ }^{18}$ using a PA : L : DMAP ratio of $1: 20: 4$ (Scheme 1; see Table S1, ESI $\dagger$ ). The neat polymerization was stirred at $130{ }^{\circ} \mathrm{C}$ under a nitrogen environment. After $5,10,15,30$, and 60 minutes, reaction vials were opened to atmosphere and cooled before dissolution in dichloromethane (DCM) and precipitation in hexanes. ${ }^{1} \mathrm{H}-\mathrm{NMR}$ spectroscopy identified successful synthesis of PA-functional oligo(D,L-lactide) (PA-ODLA) with $\sim 99 \%$ conversion of D,L-lactide after only 5 minutes of polymerization (Fig. 1a; see Fig. S3, ESI†). Integration of peaks $\mathrm{C}, \mathrm{E}$, and $\mathrm{F}$ indicated linkers were $\sim 19$ lactide units, or an average $M_{\mathrm{n}}$ of $2825 \mathrm{Da}$. However, matrix assisted laser desorption ionization time of flight mass spectrometry 


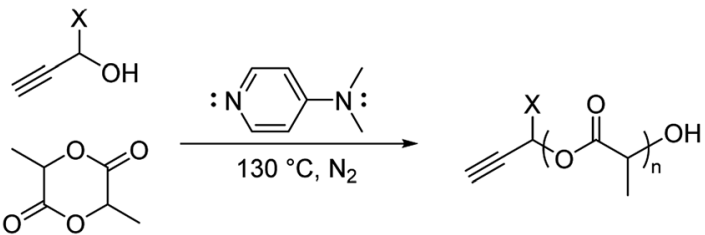

Scheme 1 Ring-opening polymerization of lactide by alcohol initiator. $\mathrm{X}=\mathrm{H}$, propargyl alcohol; $\mathrm{CH}_{3}, \alpha$-methyl propargyl alcohol.

suggested $M_{\mathrm{n}}$ was $752 \mathrm{Da}$. As $M_{\mathrm{n}}$ determined by NMR was based on average end-group analysis and assumed PA-initiated oligo(lactide), and $M_{\mathrm{n}}$ determined by MALDI analysis represented all species present, these data indicated that not all oligo(lactide) chains were initiated by PA. Rather, distinct series of peaks periodically separated by $144 \mathrm{Da}$, the $M_{\mathrm{n}}$ of lactide, were formed during polymerization $(\alpha, \beta, \gamma, \delta, \varepsilon$, and $\zeta$; Fig. $1 \mathrm{~b}$; see Table S2, ESI $\dagger)$. Peaks 72 Da less than these peaks were also identified $\left(\alpha^{\prime}-\right.$ $\left.\zeta^{\prime}\right)$. Additional reactions were conducted to identify the formed products: one with the initiator $\alpha$-methyl propargyl alcohol ( $\alpha$ MPA; see Fig. S4, ESI $\dagger$ ), and another with only D,L-lactide and DMAP but no initiator (see Fig. S9, ESI $\dagger$ ).

The desired product, PA-ODLA “ $\alpha$ ” (Fig. 1a), was formed via DMAP base activation of PA, which initiated ROP (see Fig. S5, ESI $\dagger$ ). Base activation of the alcohol was confirmed similar to
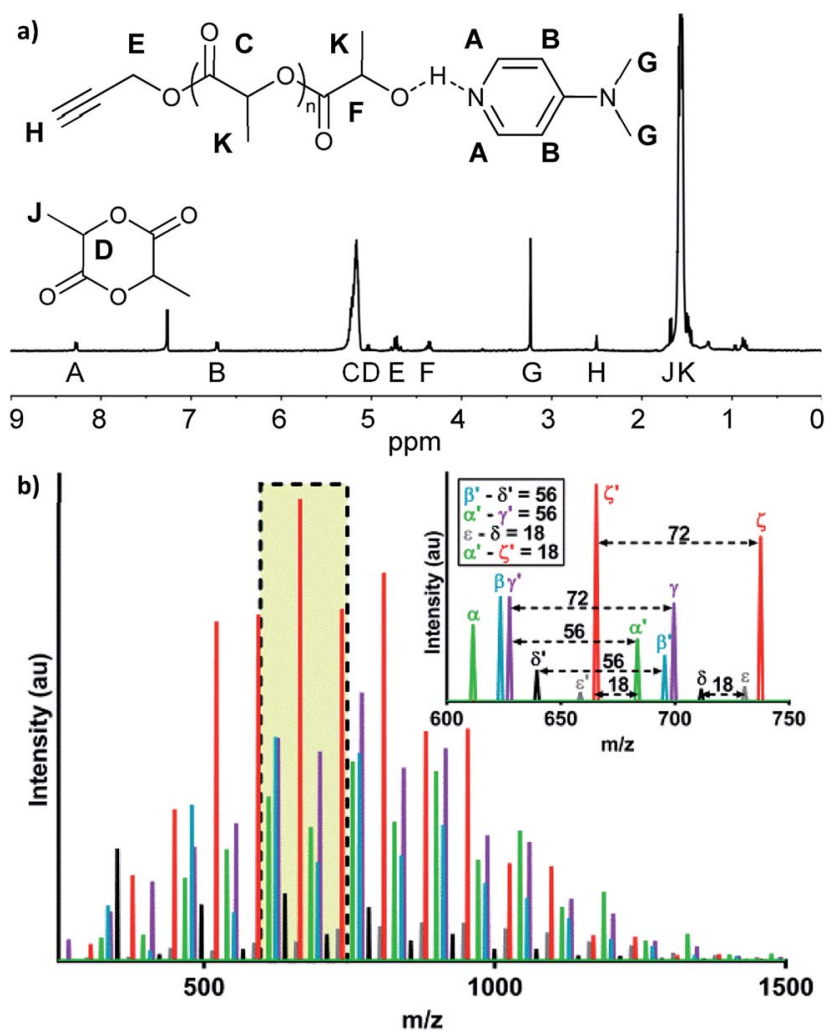

Fig. 1 Five minute polymerizations of $1: 20: 4$ propargyl alcohol: lactide: 4-dimethylaminopyridine form varied products. (a) ${ }^{1} \mathrm{H}$ NMR, with hydrogen peaks assignments shown. (b) MALDI-TOF, where colors represent peak sets that repeat every $72 \mathrm{Da}$ and the inset shows a full 144 Da peak set. previous reports ${ }^{20,31}$ using ${ }^{1} \mathrm{H}-\mathrm{NMR}$ of PA mixed with DMAP in $\mathrm{CDCl}_{3}$ to identify ppm shifts for hydroxyl groups (see Fig. S6, ESI $\dagger$ ). Peak $\alpha^{\prime}, 72$ Da less than $\alpha$, was the result of transesterification of PA-ODLA (see Fig. S7, ESI $\dagger$ ), which is a common side-reaction during ROP of lactide. ${ }^{\mathbf{1 8 2 0}}$ Two undesired products, peaks $\zeta$ and $\zeta^{\prime}$, were cyclic PA-ODLA with and without transesterification, respectively. Cyclicization increases over time during ROP of lactide $\mathrm{e}^{32-34}$ and is undesired because hydroxyl end groups are not available for subsequent conjugation. These peaks were due to radical-mediated dehydration with hydroxyl end group participation, ${ }^{35}$ as the addition of hydroquinone (HQ), a radical scavenger, eliminated peaks $\zeta$ and $\zeta^{\prime}$ (see Fig. S8, ESI $\dagger$ ). However, a peak appeared that corresponded to HQ-DMAP-ODLA and lacked alkyne functionalities for subsequent click reactions.

Another undesired product, DMAP-ODLA, or peak $\gamma$, formed via DMAP nucleophilic attack of lactide (see Fig. S9, ESI $\dagger$ ). Peak $\gamma^{\prime}$, separated by 72 Da from peak $\gamma$, resulted from transesterification of DMAP-ODLA. By conducting reactions of only DMAP and lactide, only PA and lactide, and only $\alpha \mathrm{MPA}$ and lactide, it was confirmed that DMAP can both initiate and catalyze lactide ROP, but PA and $\alpha$ MPA cannot (see Fig. S10, ESI $\dagger$ ). DMAP-ODLA formed due to PA : DMAP ratios less than 1, as previously described, ${ }^{\mathbf{1 8}}$ and is undesired because 'clickable' propargyl end groups are not present. Finally, peaks $\beta, \delta$, and $\varepsilon$ are likely ion fragments, as these peaks were only present when using MALDI in linear, but not reflector, mode (see Fig. S11, $\mathrm{ESI} \dagger)$.

To increase the amount of oligo(lactide) with alkyne and hydroxyl functionalities, side reactions were systematically addressed. It was noted that transesterification increased with time of polymerization and was greater for PA than for $\alpha$ MPA, as less nucleophilic secondary alcohols are unable to participate in transesterification reactions. ${ }^{30}$ Thus, reactions were conducted at $130{ }^{\circ} \mathrm{C}$ for 5 minutes using $\alpha$ MPA as the initiator to optimize desired product ( $\alpha$ MPA-ODLA, peak $\alpha$ ).

Ratios of $\alpha \mathrm{MPA}: \mathrm{L}$ : DMAP were investigated to mitigate undesired DMAP-initiated and cyclic ODLA (Table 1). Holding aMPA : L constant and increasing $\alpha$ MPA : DMAP increased the intensity of cyclic $\alpha$ MPA-ODLA $\zeta$ relative to DMAP-ODLA $\gamma$, but $\alpha$ MPA-ODLA $\alpha$ became negligible (Fig. 2a; see Fig. S12, ESI $\dagger$ ). Increasing $\alpha$ MPA : $L$ at a constant $\alpha$ MPA : DMAP increased the intensity of $\alpha$ relative to both $\zeta$ and $\gamma$ (Fig. 2 b; see Fig. S13, ESI $\dagger$ ).

Table 1 Characterization of 5 minute $\alpha$ MPA polymerizations. $X=\%$ conversion, $M_{n}=$ molecular weight, $\mathrm{PDI}=$ polydispersity

\begin{tabular}{lllll}
\hline$\alpha$ MPA $:$ L $:$ DMAP & $X$ & $M_{\mathrm{n}}(\mathrm{NMR})$ & $M_{\mathrm{n}}$ (MALDI) & PDI \\
\hline $1: 20: 4$ & $96 \%$ & $2040 \mathrm{Da}$ & $721 \mathrm{Da}$ & 1.16 \\
$1: 20: 2$ & $87 \%$ & $3620 \mathrm{Da}$ & $782 \mathrm{Da}$ & 1.20 \\
$1: 20: 1$ & $88 \%$ & $3150 \mathrm{Da}$ & $826 \mathrm{Da}$ & 1.23 \\
$1: 20: 0.5$ & $65 \%$ & $3120 \mathrm{Da}$ & $881 \mathrm{Da}$ & 1.23 \\
$1: 10: 1$ & $92 \%$ & $2200 \mathrm{Da}$ & $759 \mathrm{Da}$ & 1.25 \\
$1: 5: 1$ & $97 \%$ & $1470 \mathrm{Da}$ & $763 \mathrm{Da}$ & 1.16 \\
$1: 2: 1$ & $97 \%$ & $1160 \mathrm{Da}$ & $656 \mathrm{Da}$ & 1.10 \\
$1: 10: 5$ & $96 \%$ & $2050 \mathrm{Da}$ & $772 \mathrm{Da}$ & 1.11 \\
$1: 5: 2.5$ & $97 \%$ & $1550 \mathrm{Da}$ & $725 \mathrm{Da}$ & 1.12
\end{tabular}



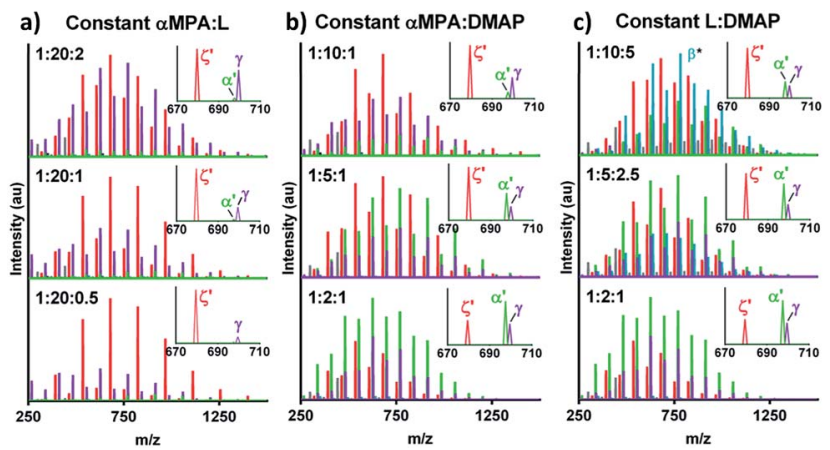

Fig. 2 Initiator, catalyst, and monomer relationships control ratios of formed products. (a) MALDI-TOF with (top to bottom) increasing aMPA : DMAP and L : DMAP. (b) MALDI-TOF with increasing $\alpha M P A: L$ and decreasing $L$ : DMAP. (c) MALDI-TOF with increasing $\alpha M P A$ : DMAP and $\alpha M P A: L$. ${ }^{*} \beta$ is a temporary ion fragment (see Fig. 1).

Similar behavior was identified when holding L: DMAP constant and increasing $\alpha$ MPA : L (Fig. 2c; see Fig. S14, ESI †े). These results suggest that $\alpha \mathrm{MPA}: \mathrm{L}$ controls cyclicization, as the distribution of $\zeta$ is similar among reactions in Fig. $2 \mathrm{a}$, and the ratio of $\zeta: \alpha$ decreases between ratios of $1: 10$ and $1: 2$ in Fig. 2b. $\alpha$ MPA : DMAP controls DMAP-ODLA generation, as the distribution of $\gamma$ is similar within Fig. $2 b$ and smallest at a ratio of $2: 1$. Finally, lower ratios of L : DMAP appear to increase $\alpha$, with $2: 1$ yielding the greatest amount of desired product $\alpha$. Altogether, higher $\alpha \mathrm{MPA}: \mathrm{L}$, higher $\alpha \mathrm{MPA}$ : DMAP, and lower $\mathrm{L}$ : DMAP ratios yield higher levels of $\alpha$ relative to $\gamma$ and $\zeta$.

Increasing the stoichiometry of lactide to initiator is commonly exploited to form linkers of various lengths to achieve differential release rates. ${ }^{24}$ To explore the utility of this approach using optimized reaction conditions, $\alpha$ MPA $: L$ ratios of $1: 2,1: 5$, and $1: 10$ were investigated using 1 mol\% DMAP (Table 2, see Fig. S15-S17, ESI $\dagger$ ). With an $\alpha$ MPA : DMAP ratio of 33 or greater, $\gamma$ was absent in all reactions. The polymerization with the highest $\alpha \mathrm{MPA}: \mathrm{L}$ ratio, $1: 2: 0.03$, had the greatest overall $\alpha: \zeta$ ratio. Interestingly, the peak $\eta$ appeared, corresponding to $\alpha$ MPA-ODLA with a $\mathrm{K}^{+}$ion, in contrast to $\alpha$ with a DMAP- $\mathrm{H}^{+}$ion adduct. There was a transition from $\eta$ to $\alpha$ over time, and $\eta$ was most abundant in $1: 2: 0.03$ reactions. This was explored further with polymerization times of 4 minutes and less (see Fig. S18, ESI $\uparrow$ ). One minute reactions showed negligible conversion of lactide monomer. After 2 minutes,

Table 2 Characterization of aMPA-initiated reactions of various stoichiometry and reaction times. $X=\%$ conversion, $M_{n}=$ molecular weight

\begin{tabular}{lllll}
\hline$\alpha$ MPA : L : DMAP & Time & $X$ & $\alpha: \zeta$ & $M_{\mathrm{n}}$ (MALDI) \\
\hline $1: 2: 0.03$ & $5 \mathrm{~min}$ & $82 \%$ & 1.1 & $619 \mathrm{Da}$ \\
& $10 \mathrm{~min}$ & $99 \%$ & 1.3 & $685 \mathrm{Da}$ \\
& $15 \mathrm{~min}$ & $99 \%$ & 1.6 & $661 \mathrm{Da}$ \\
$1: 5: 0.06$ & $5 \mathrm{~min}$ & $73 \%$ & 0.13 & $753 \mathrm{Da}$ \\
& $10 \mathrm{~min}$ & $89 \%$ & 0.23 & $727 \mathrm{Da}$ \\
$1: 10: 0.11$ & $15 \mathrm{~min}$ & $94 \%$ & 0.24 & $758 \mathrm{Da}$ \\
& $5 \mathrm{~min}$ & $32 \%$ & 0.25 & $772 \mathrm{Da}$ \\
& $10 \mathrm{~min}$ & $71 \%$ & 0.10 & $736 \mathrm{Da}$ \\
& $15 \mathrm{~min}$ & $83 \%$ & 0.08 & $747 \mathrm{Da}$
\end{tabular}
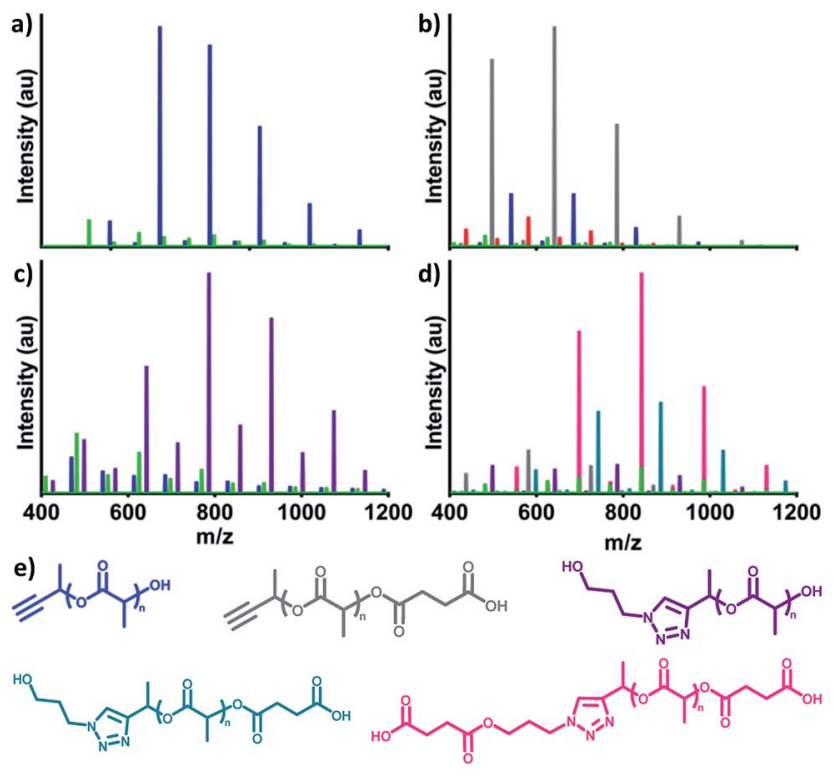

Fig. 3 Demonstration of $\alpha$ MPA-ODLA linker heterobifunctionality using MALDI-TOF analysis. (a) Polymerization to form $\alpha$ MPA-ODLA. (b) Reaction to open succinic anhydride (SA) on $\alpha M P A-O D L A$. (c) Reaction to add 3-azido-1-propanol $\left(\mathrm{N}_{3}\right)$ on aMPA-ODLA. (d) Reaction to add 3-azido-1-propanol on aMPA-ODLA-SA. (e) Chemical structures of aMPA-ODLA: blue, $\alpha$ MPA-ODLA-SA: grey, $\mathrm{N}_{3}-\alpha M P A-O D L A:$ purple, $\mathrm{N}_{3}-\alpha M P A-O D L A-S A$ : teal, SA-N $3-\alpha M P A-O D L A-S A$ : pink.

conversion was $68 \%$ and the major product was $\eta$. By 4 minutes, $\alpha$ and $\zeta$ exceeded $\eta$, suggesting that shorter reaction times are necessary to isolate linear $\alpha$ MPA-ODLA without DMAP adducts.

Finally, proof of concept conjugations demonstrated the utility of $\alpha$ MPA-ODLA as a heterobifunctional linker (Fig. 3; see Fig. S19, ESI $\dagger$ ). Following 90 seconds of polymerization of $1: 2: 0.03$ aMPA : L : DMAP (Fig. 3a), aMPA-ODLA was modified on either propargyl or hydroxyl end groups. 3-Azido-1propanol (see Fig. S20, ESI $\dagger$ ) was added to propargyl moieties via Huisgen 1,3-dipolar cycloaddition (Fig. 3b). Interestingly, only $\eta$ was shifted by $101 \mathrm{Da}$, the $M_{\mathrm{n}}$ of 3-azido-1-propanol, by MALDI analysis, suggesting that DMAP adducts in $\alpha$ interfere with propargyl modification. Hydroxyl end groups were modified to carboxylic acids using two-step, one-pot reactions whereby succinic anhydride (SA) was added following 90 seconds of lactide polymerization (Fig. 3c). These reactions were viable in either order when modifying both ends of $\alpha$ MPA-ODLA (Fig. 3d, S19d and e, see ESI $\dagger$ ). It is noted that since an alcohol was used as a model azide, both $\mathrm{N}_{3}-\alpha$ MPA-ODLA-SA and SA- $\mathrm{N}_{3}-$ $\alpha$ MPA-ODLA-SA formed during reactions. Pure $\mathrm{N}_{3}-\alpha$ MPA-ODLASA could be achieved by forming $\alpha$ MPA-ODLA-SA, removing unreacted SA, and conducting azide-alkyne conjugation.

\section{Conclusions}

This work presents a systematic design of narrowly dispersed, low molecular weight oligo(lactide) formed without metal catalysts that are difficult to completely remove during purification. Before optimization, observed MALDI $M_{\mathrm{n}}$ disagreed with $M_{\mathrm{n}}$ as determined by NMR, suggesting transesterification 
reactions were present. Previous studies investigated the singular effects of polymerization temperature, polymerization time, monomer : initiator ratio, chemical initiator, and reagent degassing time on PLA transesterification. ${ }^{36}$ This study identified the combined effects of choice of initiator, initiator : catalyst ratio, initiator : monomer ratio, and polymerization time on molecular weight, polydispersity, and relative amounts of desired and undesired products. Temperature was not changed from $130{ }^{\circ} \mathrm{C}$ due to the high melting point of D,L-lactide $\left(122{ }^{\circ} \mathrm{C}\right)$. A 90 second reaction of $1: 2: 0.03$ aMPA : L : DMAP formed oligo(lactide) with alkyne and hydroxyl functionalities available for subsequent click conjugations. Further optimization may be required to increase the reaction efficiency, as theoretical $M_{\mathrm{n}}$ does not match $M_{\mathrm{n}}$ determined by MALDI. Although studies herein investigated ROP of lactide by DMAP, the approach can be employed for similar systems (e.g. catalysis by stannous octoate or ROP of glycolide). Similarly, copper-catalyzed azide-alkyne cycloaddition (CuAAC) may be used in place of Huisgen 1,3-dipolar cycloaddition for applications in which residual copper contamination is acceptable.

\section{Conflicts of interest}

There are no conflicts to declare.

\section{Acknowledgements}

We acknowledge the National Science Foundation (NSF DGE1419118 and CBET1450987) for funding this work. We thank Prof. Wyatt Tenhaeff at the University of Rochester for advice on manuscript revisions.

\section{Notes and references}

1 C. Guan, B. Xu, S. Qiao, L. Qin, Y. Li, Z. Li, Y. Guo, Z. Sun, L. Song, R. Gao and P. I. Investigators, Cathet. Cardiovasc. Interv., 2017, 89, 520-527.

2 A. H. Salama, A. A. Mahmoud and R. Kamel, AAPS PharmSciTech, 2016, 17, 1159-1172.

3 S. Gholizadeh, J. Kamps, W. E. Hennink and R. J. Kok, Int. J. Pharm, 2017, DOI: 10.1016/j.ijpharm.2017.10.032.

4 K. Ren, M. Zhang, J. He, Y. Wu and P. Ni, ACS Appl. Mater. Interfaces, 2015, 7, 11263-11271.

5 M. Veurink, L. Asmus, M. Hennig, B. Kaufmann, L. Bagnewski, A. Heiligenhaus, E. Mendrinos, C. J. Pournaras, R. Gurny and M. Moller, Eur. J. Pharm. Sci., 2013, 49, 233-240.

6 M. Sobczak, E. Witkowska, E. Oledzka and W. Kolodziejski, Molecules, 2008, 13, 96-106.

7 L. R. Jaidev, D. R. Chellappan, D. V. Bhavsar, R. Ranganathan, B. Sivanantham, A. Subramanian, U. Sharma, N. R. Jagannathan, U. M. Krishnan and S. Sethuraman, Acta Biomater., 2017, 49, 422-433.

8 W. Lin, Y. Li, W. Zhang, S. Liu, Z. Xie and X. Jing, ACS Appl. Mater. Interfaces, 2016, 8, 24426-24432.

9 Q. Zhang, Y. Du, L. Jing, X. Liang, Y. Li, X. Li, Z. Dai and J. Tian, J. Biomed. Nanotechnol., 2016, 12, 491-502.
10 J. Xie, A. Li and J. Li, Macromol. Rapid Commun., 2017, 38(23), 1700413.

11 L. G. Leahy, J. Psychosoc. Nurs. Ment. Health Serv., 2017, 55, 19-23.

12 Y. L. Fan, H. W. Hou, H. M. Tay, W. M. Guo, P. O. Berggren and S. C. Loo, AAPS PharmSciTech, 2017, 18(7), 2648-2657.

13 P. Rafiei and A. Haddadi, Pharm. Nanotechnol., 2017, 5, 3-23.

14 S. Kaihara, S. Matsumura, A. G. Mikos and J. P. Fisher, Nat. Protoc., 2007, 2, 2767-2771.

15 J. W. Leenslag and A. J. Pennings, Makromol. Chem., 1987, 188, 1809-1814.

16 M. C. Tanzi, P. Verderio, M. G. Lampugnani, M. Resnati, E. Dejana and E. Sturani, J. Mater. Sci.: Mater. Med., 1994, 5, 393-396.

17 F. Nederberg, E. F. Connor, M. Moller, T. Glauser and J. L. Hedrick, Angew. Chem., Int. Ed. Engl., 2001, 40, 2712-2715.

18 O. Coulembier and P. Dubois, J. Polym. Sci., Part A: Polym. Chem., 2012, 50, 1672-1680.

19 K. Makiguchi, S. Kikuchi, K. Yanai, Y. Ogasawara, S. Sato, T. Satoh and T. Kakuchi, J. Polym. Sci., Part A: Polym. Chem., 2014, 52, 1047-1054.

20 J. Kadota, D. Pavlovic, H. Hirano, A. Okada, Y. Agari, B. Bibal, A. Deffieux and F. Peruch, RSC Adv., 2014, 4, 14725-14732.

21 I. V. Dimitrov, I. V. Berlinova and V. I. Michailova, Polym. J., 2013, 45, 457-461.

22 C. H. Yan, J. M. Zhang, Y. X. Lv, J. Yu, J. Wu, J. Zhang and J. S. He, Biomacromolecules, 2009, 10, 2013-2018.

23 M. Eldessouki, G. Buschle-Diller and Y. Gowayed, Des. Monomers Polym., 2016, 19, 180-192.

24 D. S. W. Benoit, C. R. Nuttelman, S. D. Collins and K. S. Anseth, Biomaterials, 2006, 27, 6102-6110.

25 S. J. de Jong, S. C. De Smedt, J. Demeester, C. F. van Nostrum, J. J. Kettenes-van den Bosch and W. E. Hennink, J. Controlled Release, 2001, 72, 47-56.

26 C. S. Proikakis, P. A. Tarantili and A. G. Andreopoulos, J. Elastomers Plast., 2002, 34, 49-63.

27 H. Fukuzaki, M. Yoshida, M. Asano and M. Kumakura, Eur. Polym. J., 1989, 25, 1019-1026.

28 Y. Liu, W. Hou, H. Sun, C. Cui, L. Zhang, Y. Jiang, Y. Wu, Y. Wang, J. Li, B. S. Sumerlin, Q. Liu and W. Tan, Chem. Sci., 2017, 8, 6182-6187.

29 H. C. Kolb, M. G. Finn and K. B. Sharpless, Angew. Chem., Int. Ed. Engl., 2001, 40, 2004-2021.

30 F. Nederberg, E. F. Connor, T. Glausser and J. L. Hedrick, Chem. Commun., 2001, 2066-2067, DOI: 10.1039/b106125a.

31 C. Bonduelle, B. Martin-Vaca, F. P. Cossio and D. Bourissou, Chemistry, 2008, 14, 5304-5312.

32 H. R. Kricheldorf, S. M. Weidner and F. Scheliga, Polym. Chem., 2017, 8, 1589-1596.

33 V. Katiyar and H. Nanavati, Polym. Chem., 2010, 1, 1491-1500. 34 G. Montaudo, M. S. Montaudo, C. Puglisi, F. Samperi, N. Spassky, A. LeBorgne and M. Wisniewski, Macromolecules, 1996, 29, 6461-6465.

35 V. T. Lipik, L. K. Widjaja, S. S. Liow, M. J. M. Abadie and S. S. Venkatraman, Polym. Degrad. Stab., 2010, 95, 2596-2602. 36 G. Schwach, J. Coudane, R. Engel and M. Vert, Biomaterials, 2002, 23, 993-1002. 